\title{
Differential Regulation of the Serotonin Transporter Gene by Lithium Is Mediated by Transcription Factors, CCCTC Binding Protein and Y-Box Binding Protein 1, through the Polymorphic Intron 2 Variable Number Tandem Repeat
}

\author{
Julian Roberts, ${ }^{1,2,3 *}$ Alison C. Scott, ${ }^{1,2 \star}$ Mark R. Howard, ${ }^{1,2}$ Gerome Breen, ${ }^{4}$ Vivien J. Bubb, ${ }^{2,3}$ Elena Klenova, ${ }^{5}$ and \\ John P. Quinn ${ }^{1,2}$ \\ ${ }^{1}$ Physiology Laboratory, School of Biomedical Science, ${ }^{2}$ Department of Human Anatomy and Cell Biology, School of Biomedical Science, and ${ }^{3}$ Neurological \\ Science, Medical School, University of Liverpool, Liverpool L69 3BX, United Kingdom, ${ }^{4}$ Medical Research Council Social Genetic and Developmental \\ Psychiatry Research Centre, Institute of Psychiatry, King's College London, London SE5 8AF, United Kingdom, and ${ }^{5}$ Department of Biological Sciences, \\ University of Essex, Wivenhoe Park, Colchester, Essex C04 3SQ, United Kingdom
}

\begin{abstract}
The serotoninergic pathways are possible targets for the action of lithium, a therapeutic agent for treatment of bipolar affective disorders. This study aimed to investigate the molecular mechanisms regulating human serotonin transporter gene (SLC6A4) expression by lithium and, specifically, the role of the variable number tandem repeat (VNTR) polymorphic region in intron 2, which is potentially a predisposing genetic factor for bipolar affective disorders. We demonstrated that addition of lithium to human JAr cells led to changes in the levels of SLC6A4 mRNA and protein. Additional investigations revealed that the intron 2 VNTR domain was a potential target for mediation of a transcriptional response to lithium. Properties of two transcription factors, CCCTC binding protein (CTCF) and Y-box binding protein 1 (YB-1), previously shown to be involved in the regulation of SLC6A4 VNTR, were found to be modulated by LiCl. Thus, levels of CTCF and YB-1 mRNA and protein were altered in vivo in response to LiCl. Furthermore, CTCF and YB-1 showed differential binding to the polymorphic alleles of the VNTR on exposure to LiCl. Our data suggest a model in which differential binding of CTCF and YB-1 to the allelic variants of the intron 2 VNTR can be regulated by lithium and in part result in differential and even aberrant expression of SLC6A4. Our study of the regulation of the SLC6A4 VNTR by lithium may improve the understanding of psychiatric disorders and enable the development of novel therapies for conditions such as bipolar affective disorder to target only the at-risk allele.
\end{abstract}

Key words: CTCF; YB-1; SLC6A4; VNTR; affective disorders; transcription; lithium

\section{Introduction}

Mutation or inappropriate expression of human $5 \mathrm{HT}$ transporter (SLC6A4) gene is postulated as an etiological factor in affective and other neurological disorders. The intron 2 variable number tandem repeat (VNTR) has been reported to be associated with mood disorders in some studies, with the most recent metaanalysis showing a significant but small effect (Cho et al., 2005; Lasky-Su et al., 2005). However, the effect is probably dependent

Received Aug. 23, 2005; revised Jan. 29, 2007; accepted Jan. 30, 2007.

This work was supported by grants from the Wellcome Trust, Biotechnology and Biological Sciences Research Council, Medical Research Council, and TCS Cellwork Ltd. (J.P.Q.); the Breast Cancer Campaign (E.K.); and the PhD studentship from University of Essex (J.R.). We are grateful to A. Lee and J. Ting for the YB-1 vector construct, H.-D. Royer for anti-YB-1 antibodies, and I. Chernukhin for providing us with the purified bvCTCF samples. We thank Karen Collard for expert technical assistance.

*J.R. and A.C.S. contributed equally to this work.

Correspondence should be addressed to either of the following: Elena Klenova, Department of Biological Sciences, University of Essex, Wivenhoe Park, Colchester, Essex C043SQ, UK, E-mail: klenovae@essex.ac.uk; or John P. Quinn, Physiology Laboratory, School of Biomedical Science, University of Liverpool, Liverpool L69 3BX, UK, E-mail: jquinn@liv.ac.uk.

DOI:10.1523/JNEUROSCI.0892-06.2007

Copyright $\odot 2007$ Society for Neuroscience $\quad$ 0270-6474/07/272793-09\$15.00/0 on specific environmental exposures, as shown for other polymorphisms in this gene (Caspi et al., 2003).

The intron 2 VNTR exists as three common allelic variants containing 9, 10, or 12 copies of a repeated 16 or 17 bp element (termed Stin2.9, Stin2.10, and Stin2.12, respectively) (see Fig. $2 A)$. We have addressed the function of this polymorphism and demonstrated that different repeat number within the VNTR supports differential expression in vitro (Fiskerstrand et al., 1999; Lovejoy et al., 2003) and both differential and tissue-specific expression in a transgenic model (MacKenzie and Quinn, 1999). In addition to VNTR copy number, the different primary DNA sequence of the VNTR elements that constitute the VNTR can support differential reporter gene expression (Lovejoy et al., 2003). Our most recent report has demonstrated that the SLC6A4 intron 2 VNTR is bound and regulated by the transcription factor Y-box binding protein 1 (YB-1) (Klenova et al., 2004) a member of the Y-box binding proteins (Wolffe et al., 1992; Wolffe, 1994; Swamynathan et al., 2002; Kohno et al., 2003), and this regulation is modulated by the transcription factor CCCTC binding protein (CTCF) (Klenova et al., 2004), a known binding partner of YB-1 (Chernukhin et al., 2000). CTCF, in addition to transcriptional 
activation or silencing in a context-dependent manner, organizes epigenetically controlled chromatin insulators regulating imprinted genes (Klenova et al., 1993; Filippova et al., 1996; Ohlsson et al., 2001; Klenova et al., 2002).

We hypothesized that the intron 2 VNTR is a target both for physiological stimuli and pharmaceutical agents that would alter SLC6A4 levels or patterns of expression correlated with the progression of affective disorders. To test this hypothesis, we addressed whether the intron 2 VNTR was a target for lithium regulation using the human cell line JAr, which endogenously express SLC6A4, as a model system (Heils et al., 1995) and assessed the role of CTCF and YB-1 in that regulation. Lithium has been used as a mood-stabilizing drug for the treatment of manic episodes and depression. The targets of lithium are varied and clearly point to lithium modifying signal transduction pathways (Chen et al., 2000; Shamir et al., 2003; Tsuji et al., 2003), which would alter the complement of active transcription factors in the cell (Ikonomov and Manji, 1999). We demonstrate that the intron 2 VNTR is a target for mediating a transcriptional response to $\mathrm{LiCl}$ via (at least in part) the transcription factors CTCF and YB-1. In vivo, transcriptional variation was correlated with differential binding of both CTCF and YB-1 to the distinct VNTR variants after exposure to $\mathrm{LiCl}$, and we postulate that this could lead to differential allelic gene expression.

\section{Materials and Methods}

Plasmids. The expression constructs used for in vitro production of recombinant YB-1 and CTCF were as described previously (Klenova et al., 2004). The human CTCF (hCTCF) expression construct was generated by subcloning hCTCF into the $\mathrm{pCI}$ expression vector (Promega, Madison, WI). The YB-1 episomal expression construct was generated by subcloning the YB-1 cDNA into pREP9 (Invitrogen, San Diego, CA) from pSV-YB-1, a kind gift from J. Ting (Lineberger Comprehensive Cancer Center, University of North Carolina, Chapel Hill, NC). The $\beta$-galactosidase expression vector pCH110 (Amersham Biosciences, Piscataway, NJ) was used as a control and to normalize for protein expression. The VNTR reporter gene constructs were produced by cloning the 9,10 , and 12 copy number VNTRs into the multiple cloning site of the pGL3-Promoter vector (pGL3p) (Promega). A neomycin resistance cassette was also inserted to enable the generation of stable cell lines.

Cell culture, stable and transient transfections, and Luciferase assays. JAr cells (ATCC HTB-144; American Type Culture Collection, Manassas, VA) were maintained as monolayers in RPMI (BioWhittaker, Walkersville, $\mathrm{MD}$ ) supplemented with $10 \%$ heat-inactivated fetal calf serum (HyClone, Logan, UT), $1 \mathrm{mg} / \mathrm{ml}$ glucose, and $1 \mathrm{~mm}$ sodium pyruvate. Transformed human epithelial kidney cells (293T) (ATCC CRL-1573; American Type Culture Collection) were maintained in DMEM supplemented with $10 \%$ fetal calf serum and $50 \mu \mathrm{g} / \mathrm{ml}$ gentamycin.

For stable transfections, cells were transfected using Transfast transfection reagent (Promega), according to the manufacturer's protocol. Briefly, cells were seeded into six-well plates $24 \mathrm{~h}$ before transfection, and then incubated with $1 \mathrm{ml}$ of serum-free media per well containing DNA and the lipid reagent for $2 \mathrm{~h}$. Then, an additional $3 \mathrm{ml}$ of media containing serum was added and cells were incubated overnight. Cells were thereafter fed as necessary. After 48 h growth, G418 was added to the growth media to select for cells that had integrated the expression plasmid. Stably transfected JAr cells were maintained in this medium supplemented with $400 \mu \mathrm{g} / \mathrm{ml} \mathrm{G418.}$

For transient cotransfection assays, $10^{5}$ cells were seeded in 12 -well plates, and then transfected according to the calcium phosphate method (Sambrook and Russell, 2001). Cells were then harvested and assayed using the Luciferase Assay System according to the manufacturer's instructions (Promega). Luminescence was measured using a Labsystems Luminoskan luminometer (Life Sciences, Helsinki, Finland). To normalize for cell number and transfection efficiency, $0.25 \mu \mathrm{g}$ of $\beta$-galactosidase marker gene plasmid ( $\mathrm{pCH} 110$ ) was included per well in the transfection solution. $\beta$-Galactosidase assays and normalization of luciferase were performed as described previously (Lovejoy et al., 2003; Klenova et al., 2004). Mean and SD were calculated from the results of three experiments performed in triplicate.

Transfection with short interfering RNA. CTCF Smartpool and nontargeting Smartpool were purchased from Dharmacon RNA technologies. JAr cells were seeded in 12 -well plates using $10^{5}$ cells per well and $100 \mathrm{nM}$ short interfering RNA (siRNA) was transfected with Dharmafect reagent 1 according to the manufacturer's protocol. Cells were harvested at $48 \mathrm{~h}$ after transfection and total RNA was isolated using the Gentra RNA isolation kit according to the manufacturer's instructions and was subsequently used for real-time PCR.

Lithium treatment. A sterile stock solution of $4 \mathrm{M} \mathrm{LiCl}$ was prepared in water. To treat cells, this was diluted using medium to construct a concentration response curve. JAr cells were grown to $80 \%$ confluence in 6 or 24 -well plates before being serum starved ( $0.1 \%$ serum) for $24 \mathrm{~h}$. Cells were incubated in media containing varying concentrations of $\mathrm{LiCl}$ overnight, and then allowed an overnight recovery phase, during which cells were returned to media containing $10 \%$ serum. Cells were harvested as described above for luciferase assays or RNA was extracted, as described below. Each set of conditions was performed in quadruplicate, and the mean and SEM were calculated from three separate experiments.

Chromatin immunoprecipitation. DNA and protein from $10^{7} \mathrm{JAr}$ cells were cross-linked with $1 \%$ formaldehyde at room temperature with agitation for $10 \mathrm{~min}$. Chromatin immunoprecipitation (ChIP) was performed essentially as described previously (Kuo and Allis, 1999; Ohlsson et al., 2001). The antibodies used were the following: monoclonal antiCTCF (BD Transduction Laboratories, Lexington, KY), polyclonal antiYB-1 (Santa Cruz Biotechnology, Santa Cruz, CA), and anti- $\alpha$-tubulin (Sigma, St. Louis, MO). Briefly, cross-linking was quenched by addition of $\mathrm{NH}_{4} \mathrm{OH}$ to $0.5 \%$ and nuclei were prepared and lysed in $250 \mu$ l of nuclei lysis buffer (50 mm Tris-Cl, pH 8.1, 10 mm EDTA, 1.5\% SDS, and protease inhibitor mixture). Chromatin was sonicated by $10 \times 1 \mathrm{~min}$ pulses using a Vibracell sonicator. Efficiency of sonication was determined by agarose gel electrophoresis and chromatin absorbance at $A_{260} / A_{280}$. Samples were diluted in ChIP buffer (0.01\% SDS, 1.1\% Triton X-100, $1.2 \mathrm{~mm}$ EDTA, $15.0 \mathrm{~mm}$ Tris-Cl, $\mathrm{pH} 8.1,150 \mathrm{~mm} \mathrm{NaCl}$, protease inhibitors) to a concentration of $1 \mu \mathrm{g} / \mu \mathrm{l}$. Blocked fast-flow protein A-Sepharose (Sigma) was added, and the samples were incubated at $4^{\circ} \mathrm{C}$ overnight. Supernatants were then analyzed using appropriate antibodies. The amount of antibody required for immunoprecipitation was determined using the following formula: $(1 /$ Western titer $\times 4) \times\left(A_{260} / A_{280}\right) \times$ $(1 /[\mathrm{DNA}]($ micrograms/microliter $)) \times$ sample volume $($ microliters $)=$ micrograms of antibody required. ChIP cross-linking was reversed by incubation at $67^{\circ} \mathrm{C}$ for $6 \mathrm{~h}$. The samples were precipitated at $-20^{\circ} \mathrm{C}$ overnight, and the DNA was purified before subsequent PCR analysis.

PCR and RT-PCR. DNA primers for amplification of the Stin2 VNTR from genomic DNA were as follows: Stin2 VNTR [forward (for)], 5' gtcagtatcacaggctgcgag- $3^{\prime}$; Stin2 VNTR [reverse (rev)], 5' tgttcctagtcttacgccagtg- $3^{\prime}$. PCR was performed using KOD hot start DNA polymerase (Novagen, Madison, WI) in standard reaction mixture supplemented with $6 \%$ DMSO. Cycles used were as follows: $98^{\circ} \mathrm{C}$ for $3 \mathrm{~min}$, 40 times $\left(98^{\circ} \mathrm{C}\right.$ for $1 \mathrm{~min}, 55^{\circ} \mathrm{C}$ for $30 \mathrm{~s}, 68^{\circ} \mathrm{C}$ for $\left.30 \mathrm{~s}\right), 68^{\circ} \mathrm{C}$ for $3 \mathrm{~min}$. RT-PCR was performed using $10^{6} \mathrm{JAr}$ cells. Briefly, cells were harvested $72 \mathrm{~h}$ after transfection, and cytosolic RNA was extracted using the RNAeasy kit (Qiagen, Hilden, Germany), followed by the one-step RTPCR kit (Novagen). Primers were designed that would generate a fragment spanning exons 3 and 4 of SLC6A4 mRNA, namely, (for), 5'ggacagtaccaccgaaatggatgc- $3^{\prime}$, and (rev), 5'-ggtgatgttgtcctcggagaag- $3^{\prime}$. PCR conditions were as above.

Quantitative RT-PCR. Total RNA was extracted using the RNA Isolation kit (Gentra, Minneapolis, MN), and cDNA was prepared using the Reverse Transcription System (Promega); both were followed according to the manufacturers' protocol; cDNA was then adjusted to provide 200 ng per quantitative RT-PCR (Q-PCR) assay. Quantitative real-time PCR was performed using a Opticon qPCR machine (GRI, Braintree, Essex, UK) and the Dynamo SYBR Green qPCR kit (Finnzymes, Espoo, Finland). For each experiment, a standard curve for each primer set was generated and used to derive the relative amounts in the unknown samples. The content of unknown samples was calculated and normalized to 
the amount of the housekeeping gene, glyceraldehyde-3-phosphate dehydrogenase (GAPDH). The primer sequences used were as follows: GAPDH, (for) $5^{\prime}$-accacagtccatgccatcac- $3^{\prime}$ and (rev) $5^{\prime}$-tccaccaccctgttgctgta-3'; CTCF (for) $5^{\prime}$-agatcatgatttccagccca- $3^{\prime}$ and (rev) $5^{\prime}$-tgtgacagttcatgtgcaaga-3'; YB-1 (for) $5^{\prime}$-gacgtaagtcccgccgattcatcc- $3^{\prime}$ and (rev) $5^{\prime}$-ctctttgggttctaccctgtcagtgc- $3^{\prime}$; SLC6A4 (for) $5^{\prime}$-ggacagtaccaccgaaatggatgc-3' and (rev) $5^{\prime}$-ggtgatgttgtcctcggagaag- $3^{\prime}$. Primers were obtained from MWG Biotech (High Point, NC). BLASTN searches confirmed the total gene specificity of the primer sequences chosen. Thermal cycling conditions were as follows: $95^{\circ} \mathrm{C}$ for $10 \mathrm{~min}$, followed by 45 cycles of amplification, consisting of $94^{\circ} \mathrm{C}$ for $10 \mathrm{~s}, 60^{\circ} \mathrm{C}$ for $20 \mathrm{~s}, 72^{\circ} \mathrm{C}$ for $20 \mathrm{~s}$ followed by data acquisition. Results of the Q-PCR assays were analyzed using software supplied with the Opticon machine. The default settings of the program were used to define the baseline value for analysis of the raw data. The expression of the target genes was normalized with respect to 1000 copies of GAPDH or $\beta$-actin and was calculated using Microsoft Excel (Microsoft, Redmond, WA). Each experiment was performed in triplicate, and each set of samples was assayed in duplicate, from which the average and SD were calculated.

EMSA. DNA fragments for EMSA were amplified using the KOD hot start DNA amplification system (Novagen), separated on agarose gels, and purified using the Qiagen gel extraction kit as recommended by the manufacturer. These fragments were end-labeled with $\left[\gamma_{-}{ }^{32} \mathrm{P}\right]$ ATP in a standard T4 polynucleotide kinase reaction as described previously (Klenova et al., 2004). Recombinant YB-1 and CTCF were isolated from Escherichia coli BL21 (DE3) and baculoviral systems, respectively, and the EMSA was performed according to Chernukhin et al. (24).

Western blotting analysis. Transfected cells were lysed in SDS-urea lysis buffer [ $0.1 \mathrm{~m}$ Tris-Cl, pH 6.8, $7 \mathrm{~m}$ urea, $10 \% \beta$-mercaptoethanol, $4 \%$ SDS, $0.01 \%(\mathrm{w} / \mathrm{v})$ phenol red] after transfection. Samples were separated on $10 \%$ resolving polyacrylamide gels, blotted, and probed with anti-CTCF (BD Transduction Laboratories; Abcam, Cambridge, MA), anti-YB-1 (a kind gift from H.-D. Royer, Breast Cancer Research, Caesar, Bonn, Germany), anti-SLC6A4 (Chemicon International, Temecula, CA), anti- $\alpha$-tubulin, and anti- $\beta$-actin (both from Sigma). Detection was performed with enhanced chemiluminescence reagent (Amersham Biosciences) according to the manufacturer's instructions. Quantification of the bands was performed by using the Image J software (http://rsb.info. nih.gov/ij/), and values were obtained from the ratios CTCF: $\alpha$-tubulin, YB-1: $\alpha$-tubulin, and SLC6A4: $\alpha$-tubulin, or CTCF: $\beta$-actin, YB-1: $\beta$ actin, and SLC6A4: $\beta$-actin.

Statistical analysis. For the dose-response, the data were analyzed using GraphPad Prism software to calculate ANOVA in conjunction with Dunnet's multiple comparison test. Differences were considered significant at a value of $p<0.05$. Statistical differences between the means of two groups were determined by Student's $t$ test; results with a value of $p \leq$ 0.05 were assessed as significant. Values were statistically analyzed using Microsoft Excel XP. Exploratory ANOVA analyses and other tests were performed in SPSS, version 12.

\section{Results}

Lithium modulates expression of the endogenous SLC6A4

gene and the transcription factors YB- 1 and CTCF

The human placental cell line JAr has been used extensively to address SLC6A4 function because it expresses the endogenous gene (Heils et al., 1995; Bradley and Blakely, 1997). We therefore analyzed whether exposure of the cells to lithium, a characterized modulator of behavior, would modulate endogenous SLC6A4 expression. Concentrations of $1-5 \mathrm{~mm} \mathrm{LiCl}$ were used, because at higher concentrations we observed nonspecific metabolic changes and changes in cell survival. $\mathrm{LiCl}$ had differential effects on endogenous SLC6A4 expression when measured by Q-PCR; there is a dose-dependent regulation of expression $(F=6.59 ; p=$ 0.004) (Fig. 1A). We have previously shown that the transcription factors CTCF and YB-1 can modulate reporter gene expression supported by the SLC6A4 intron 2 VNTR (Klenova et al., 2004); therefore, we addressed whether the endogenous expression of CTCF and YB-1 was altered in JAr cells by LiCl. As shown
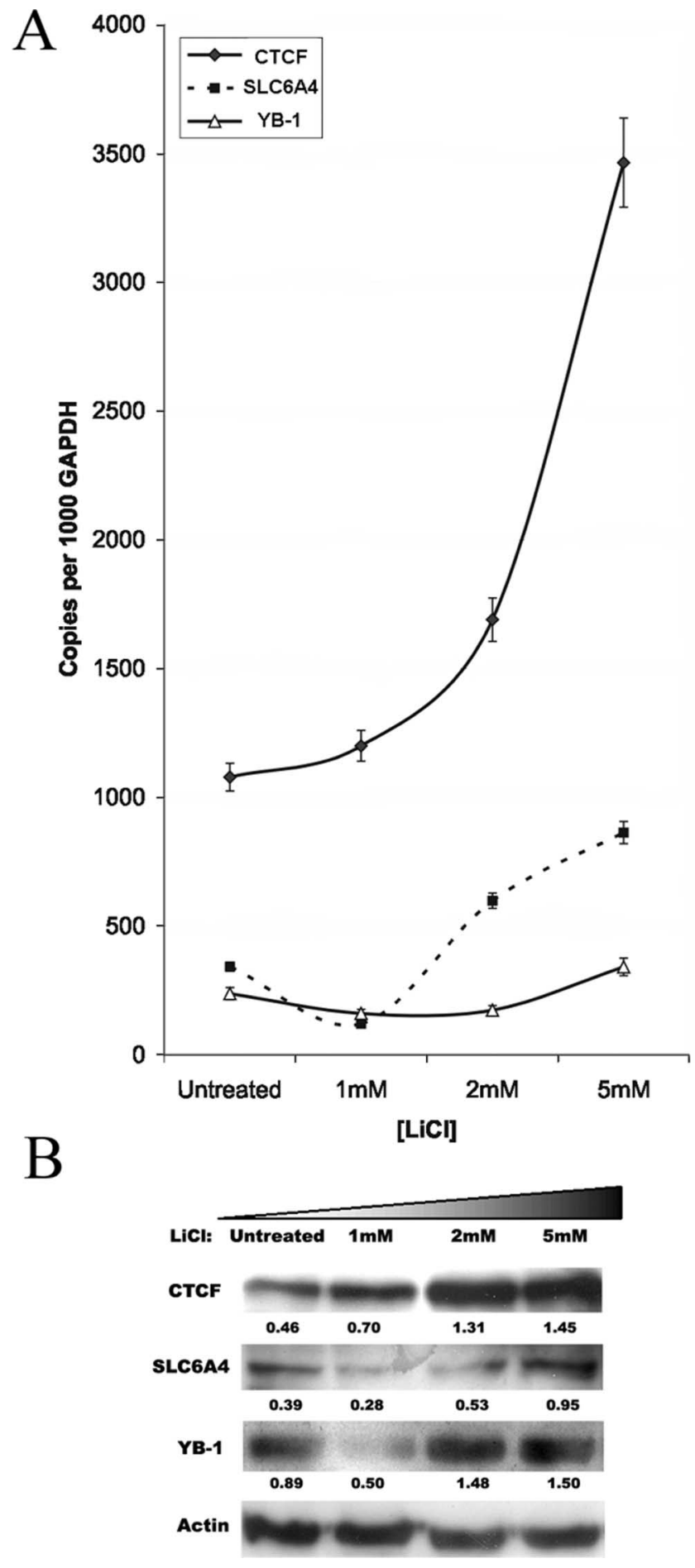

Figure 1. $\quad A, Q-P C R$ of selected genes (SLC6A4, YB-1, and CTCF). Total RNA was extracted from JAr cells after exposure to varying concentrations of $L i C l$ as shown, $C D N A$ was synthesized, and Q-PCR was performed as described in Materials and Methods. The expression of the target genes was normalized with respect to 1000 copies of GAPDH mRNA. Each point on the curve is the average of three experiments performed in duplicate. Error bars indicate SD. A strong significance of $p<0.01$ versus untreated for all treatment groups was ascertained using a twofactor ANOVA analysis. As shown, the varying $\mathrm{LiCl}$ concentrations have differential effects on the expression of RNA from each of the three genes. $\boldsymbol{B}$, Western analysis of JAr cells after exposure to varying concentrations of $\mathrm{LiCl}$ as shown. The same membrane was also probed with the $\beta$-actin antibody (loading control). The images were quantified using the Image J software. The ratios of the intensity of the CTCF, SLC6A4, and YB- 1 bands over the intensity of the corresponding $\beta$-actin bands were determined. Numbers below each lane show these results. This Western is representative of three separate Western blot analyses. 
in Figure $1 A$, the expression of both of these factors was also differentially modulated by LiCl. Interestingly, the changes in the expression levels of YB-1 and CTCF were significant and similar in direction to that of SLC6A4 (YB1, $F=10.91, p<0.001$; CTCF, $F=10.38, p<0.001$ ), with an increase in both cases. Similar data were obtained when the samples were normalized to actin mRNA (supplement 1, available at www.jneurosci.org as supplemental material). No change in GAPDH mRNA was observed, indicating that this was not a general effect of $\mathrm{LiCl}$ on gene expression (supplement 2, available at www.jneurosci.org as supplemental material). These data also are consistent with the fact that we saw no toxicity over the range of lithium concentrations that were used. Lithium concentrations used clinically are normally between 0.5 and $1.4 \mathrm{~mm}$ (Shaldubina et al., 2001); we included $1 \mathrm{~mm}$ and extended that concentration to observe more robust changes. However, we did see metabolic changes at 10 and $20 \mathrm{~mm} \mathrm{LiCl}$, and these data were not included in the analysis.

To determine whether the changes in mRNA expression level were reflected in protein concentration of the factors, Western analysis was performed under the same conditions. As can be seen in Figure $1 B$, the protein expression mirrors exactly the changes observed in gene expression.

\section{Lithium is a modulator of reporter gene expression directed by the Stin 2 VNTR}

Lithium is a modulator of reporter gene expression directed by the Stin2 VNTR. The modulation of CTCF and YB-1 by $\mathrm{LiCl}$ suggests that the intron 2 VNTR could mediate a transcriptional response to $\mathrm{LiCl}$. To investigate this proposition, stable cell populations containing the three most common Stin2 VNTR allelic variants $(9,10$, and 12 copies) (Fig. $2 A)$ in the luciferase reporter gene construct pGL3p were generated. Exposure to $\mathrm{LiCl}$ caused a significant decrease in luciferase activity in all three VNTR variants, but not in the pGL3p alone control (Fig. $2 B$ ). However, only the stable cell line with the 9 copies repeat demonstrated a linear reduction in luciferase activity (Pearson's $r=-0.498 ; p<$ 0.001 ), with the 10 repeat cell line showing a significant reduction of luciferase activity in response to lithium, which did not increase when higher concentrations were applied $(t=2.95 ; p=$ $0.006)$. Furthermore, the 10 repeat cell line did show a significantly reduced response (a $20 \%$ reduction vs $\sim 32 \%$ for each of the other VNTR cell lines) to lithium presence/absence versus the 9 and 12 cell lines $(t=2.21, p=0.03$ for 10 versus 9 and $t=2.35$, $p=0.02$ for 10 vs 12$)$. The control cell line did not show a significant difference before or after lithium $(p>0.05$ on $t$ test for presence or absence of lithium). Furthermore, the reduction in luciferase activity was seen after treatment with $1 \mathrm{~mm}$ lithium $(p<0.05$ vs untreated) and became more pronounced after treatment with 2 and $5 \mathrm{~mm}$ lithium (both $p<0.01$ vs untreated). We did not compare the response of the VNTR variants $(9,10$, or 12 ), because they are not directly comparable with one another, because we have yet to develop controls for parameters such as copy number of integrant or location of insertion in the chromatin. We examined these difference by ANOVA and found that, overall, all three stable VNTR cell lines but not the control line show a stronger response to the presence of absence of lithium rather than its absolute concentration $(F=2.174, p=0.09$ for lithium concentration; $F=5.717, p=0.018$ for lithium presence vs absence).

\section{CTCF and YB-1 coregulate the SLC6A4 intron 2 VNTR in reporter gene assays}

We previously demonstrated that CTCF and YB-1 can differentially affect Stin2 VNTR function to support reporter gene activ-
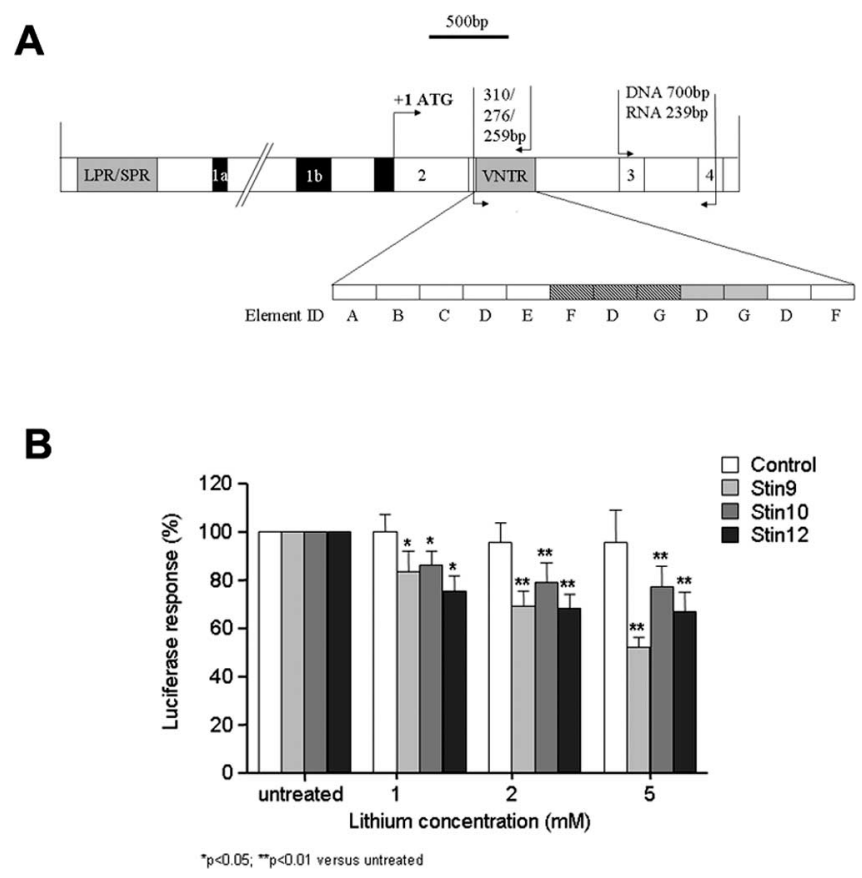

Figure 2. $\boldsymbol{A}$, Diagram of the $5^{\prime}$-region of the human SLC6A4 gene. Gray boxes, Tandem repeats/repeat elements; black boxes, noncoding exons; numbered open boxes, coding exons; white open boxes, intronic/intergenic sequences. Element IDs refer to the individual sequences that occur within the intron 2 VNTR. Positions of primers for Q-PCR are indicated by arrows. $\boldsymbol{B}$, $\mathrm{LiCl}$ modulates transcriptional activities of the three VNTR variants (Stin2.9, Stin2.10, and Stin 2.12) in stably transfected JAr cells. The cells containing stably integrated VNTR-driven luciferase constructs were treated with $\mathrm{LiCl}$, harvested, and assayed for luciferase activity as described in Materials and Methods. The luciferase activity of the lithium-treated cells is presented as a percentage, in which the untreated cells are 100\%. Each bar represents the mean of three experiments performed in quadruplicate, and the error bars indicate SEM. Significant reduction in luciferase activity was seen after treatment with $1 \mathrm{~mm}$ lithium $\left({ }^{*} p<0.05\right.$ vs untreated) and 2 and 5 mm lithium (both ${ }^{* *} p<0.01$ vs untreated), as confirmed by a two-factor ANOVA analysis.

ity in cell lines that do not demonstrate endogenous SLC6A4 expression, namely, $293 \mathrm{~T}$ and COS7 cells (Klenova et al., 2004). We repeated these experiments using transient transfection of JAr cells. Figure $3 A$ illustrates the different levels of reporter gene expression supported by the distinct VNTRs in the 293T and JAr cell lines. In both cell lines, the 12 copy VNTR supported much lower levels of gene expression.

Expression of exogenous YB-1 increased reporter gene expression in JAr cells in all three variants, as seen previously in $293 \mathrm{~T}$ cells (Klenova et al., 2004). However, in contrast to our previous data in $293 \mathrm{~T}$ cells in which CTCF alone had little effect on VNTR function (Klenova et al., 2004), in JAr cells we observed a dramatic increase in reporter gene expression to greater levels than that supported by YB-1 (Fig. 3B). Previously, we observed that coexpression of YB-1 and CTCF results in antagonism of their action and an ablation of the observed increased reporter gene expression by each individual factor (Klenova et al., 2004); similarly, here in JAr cells, coexpression ablated the increased reporter gene expression (Fig. 3B).

\section{CTCF differentially modulates expression of the endogenous SLC6A4}

We next addressed whether CTCF and YB-1 would influence expression from the endogenous SLC6A4 gene. To investigate this, expression constructs for CTCF and $\beta$-galactosidase were transfected into JAr cells and the levels of SLC6A4 mRNA were 
A

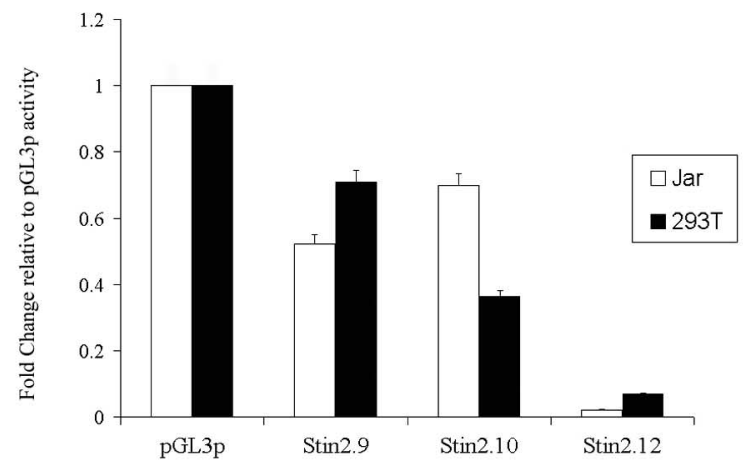

$\mathrm{B}$

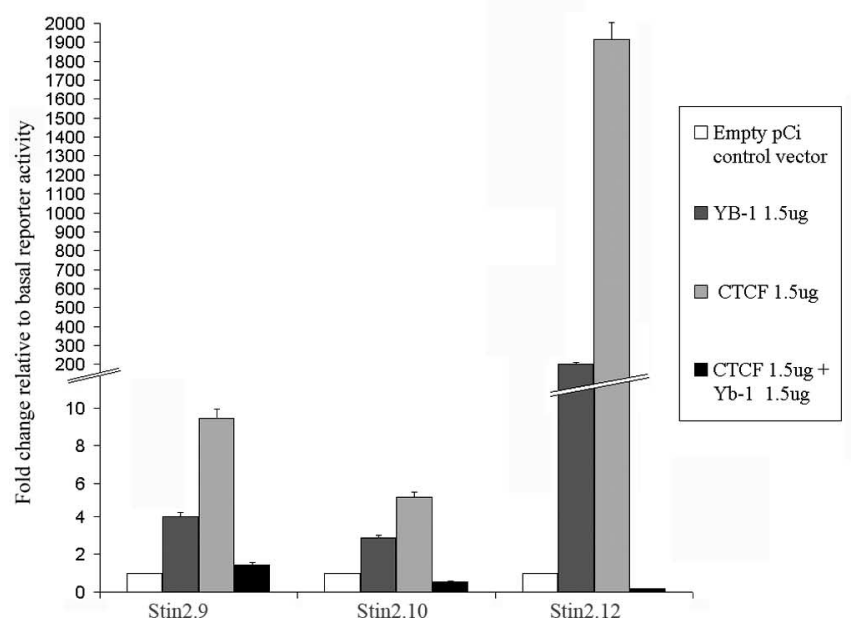

Figure 3. A, The Stin2 VNTR differentially represses transcription in reporter gene assays. JAr or 293T cells were transiently transfected with the constructs including VNTR allelic variants (Stin2.9, Stin2.10, and Stin2.12) fused to Luciferase gene, harvested, and assayed for luciferase activity as described in Materials and Methods. Bars represent fold changes of luciferase activity in the cells transfected with the VNTR-Luciferase constructs compared with the control pGL3p (taken as 1; columns at the far left side of the graph). Each bar shows an average of three experiments performed in triplicate. Error bars indicate SD. Repression by all three VNTR variants in comparison with the control vector pGL3 was significant in both 293T cells $(p<0.001)$ and JAr cells $(p<0.001)$ as shown by Student's $t$ test. $\boldsymbol{B}$, The Stin2 VNTRs are differentially regulated by the transcription factors (TCF and YB-1. Bars represent fold changes of luciferase activity in the cells transfected with the VNTR-Luciferase constructs and vectors expressing 1.5 $\mu \mathrm{g}$ of CTCF and/or YB-1 compared with the control cells transfected with the reporter only (taken as 1; bars at the left side of each series). Each bar shows an average of three experiments performed in triplicate. Error bars indicate SD. As assessed by Student's $t$ test, significant activation by CTCF $(p<0.001)$ and YB-1 $(p<0.001)$ with all three VNTR variants and significant repression by a combination of CTCF and YB-1 $(p<0.001)$ with Stin2.10 and Stin2.12 were achieved, compared with the control (empty pCi vector).

measured by Q-PCR, using primers located as outlined in Figure $2 \mathrm{~A}$. Before transfection, low but detectable levels of SLC6A4 gene mRNA were observed; however, this dramatically increased after the addition of the CTCF expression construct (Fig. 4A). Treatment of JAr cells with the CTCF Smartpool siRNA resulted in ablation of expression of both CTCF and SLC6A4 mRNA, whereas the nontargeting siRNA had no effect (Fig. $4 A$ ). We also tested whether overexpression of $\mathrm{YB}-1$ and $\beta$-galactosidase would alter the level of SLC6A4 mRNA; transfection of the YB-1 and $\beta$-galactosidase expression constructs into JAr cells did not lead to any changes in the level of SLC6A4 mRNA (data not shown).

\section{A}
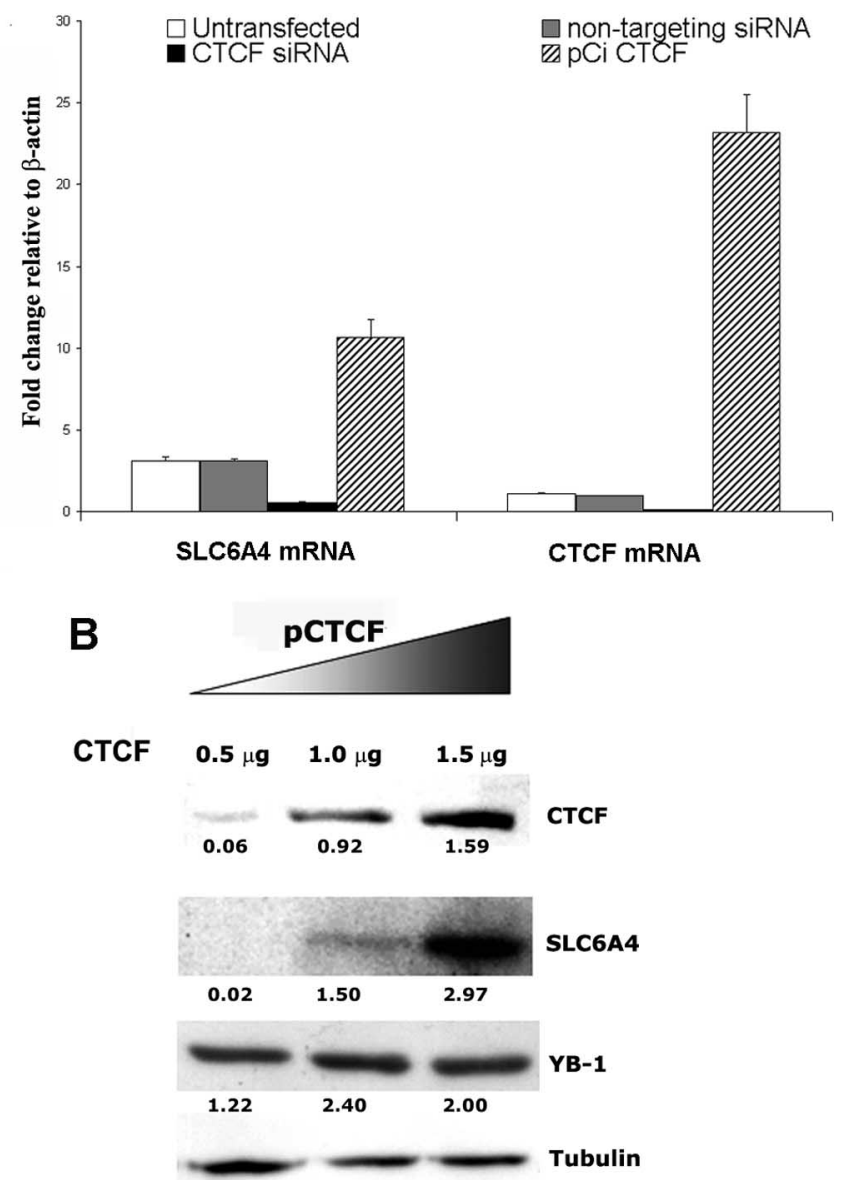

Figure 4. CTCF modulates expression of the endogenous SLC6A4 in JAr cells. A, Analysis of SLC6A4 and CTCF mRNA expression by Q-PCR. Experiments with the CTCF siRNA and transfection with the CTCF expressing vector were performed on $10^{5} \mathrm{JAr}$ cells; RNA was harvested $48 \mathrm{~h}$ after transfection, CDNA was prepared, and Q-PCR was performed. Each bar is the average of three experiments performed in duplicate. Error bars indicate SD. B, Western analysis of JAr cells transfected with CTCF as per transient transfections. The images were quantified using the Image I software. The ratios of the intensity of the CTCF, SLC6A4, and YB-1 bands over the intensity of the corresponding $\alpha$-tubulin bands were determined. Numbers below each lane show these results. This Western is representative of three separate Western blot analyses.

The increase in expression of SLC6A4 mRNA in response to increased CTCF levels was reflected in Western analysis: a dramatic increase in SLC6A4 protein level was observed when CTCF was overexpressed (Fig. 4B). However, increased CTCF expression had no significant affect on the levels of the endogenous YB-1 protein. There was no increase in $\alpha$-tubulin levels when measured as a control in the same Western analysis, indicating that this was not a general effect on protein levels attributable to overexpression of CTCF (Fig. 4B).

\section{Differential binding of YB-1 and CTCF to distinct VNTR variants}

We previously demonstrated that YB-1 can bind directly to the SLC6A4 VNTR and that CTCF can affect binding by interacting with the CSD (cold shock domain) of YB-1 (Klenova et al., 2004). In this study, we further investigated CTCF binding to the VNTR using purified baculovirus CTCF (bvCTCF) in EMSA. We found that bvCTCF can bind specifically to all three variants (Fig. $5 A$ ). 
The binding to all three variants was efficiently competed out using a DNA fragment containing the fourth CTCF binding site from the H19 ICR (Kanduri et al., 2002), which demonstrated the specificity of the interaction observed with the VNTR. YB-1 interaction with the three VNTR variants was confirmed in this assay (Fig. 5Ai-iii, lanes 2 and 3). Based on the competition assay using the CTCF binding site from the H19 ICR against the CTCF complexes formed on the VNTR (indicated by arrows), CTCF binds the 12 copy VNTR with the lowest affinity, because full competition is observed with 1 log less competitor.

To substantiate our finding that both CTCF and YB-1 could interact with the Stin2 VNTR, we analyzed these interactions in vivo, in JAr cells, using ChIP assays. PCR analysis demonstrated that the JAr cell line is heterozygous at this locus containing alleles for 10 and 12 VNTR variants as shown in Figure 5B. Strikingly, in JAr cells under basal growth conditions, YB-1 and CTCF interact predominantly with the Stin2.10 allele as shown by titration of template and antibody both in the presence and absence of serum (Fig. 5B). To validate the results of the ChIP analysis obtained with the SLC6A4 VNTR, multiple characterized CTCF sites from other genes were also tested under the same conditions and CTCF binding was detected for all of these sites (data not shown).

When cells were exposed to $\mathrm{LiCl}$ at 1 and $2 \mathrm{~mm}$, we observed a dramatic change in the interaction of both YB- 1 and CTCF with the specific allelic variants of the VNTR. Interaction was now predominantly with the Stin 2.12 allele rather than the Stin2.10 allele (Fig. 5C). At $5 \mathrm{~mm} \mathrm{LiCl,}$ binding of these factors could not be detected to either allele.

\section{Discussion}

Lithium is effective in the treatment of mania and in the long-term prophylaxis of bipolar disorder (Baastrup et al., 1970), and serotoninergic pathways are strong candidates for its action (Collier et al., 1996; Lerer et al., 2001). Consistent with this, in our model, the expression levels of the endogenous SLC6A4 gene varied in JAr cells in response to $\mathrm{LiCl}$ (Fig. 1). Lithium has been previously shown to regulate enzymes playing important roles in signal transduction pathways (Agam and Shaltiel, 2003; Shamir et al., 2003; Tsuji et al., 2003) and transcription factors such as AP1 (Tamura et al., 2002). To this list we add the transcription factors CTCF and YB-1. Importantly, CTCF and YB-1 pro-

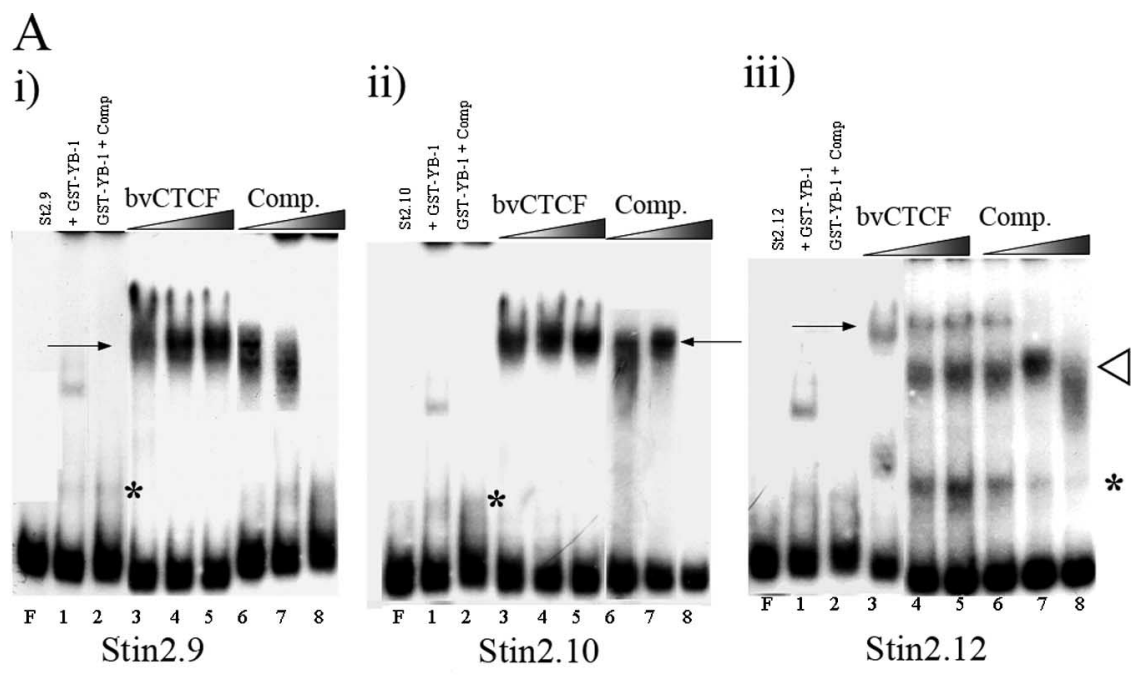

B

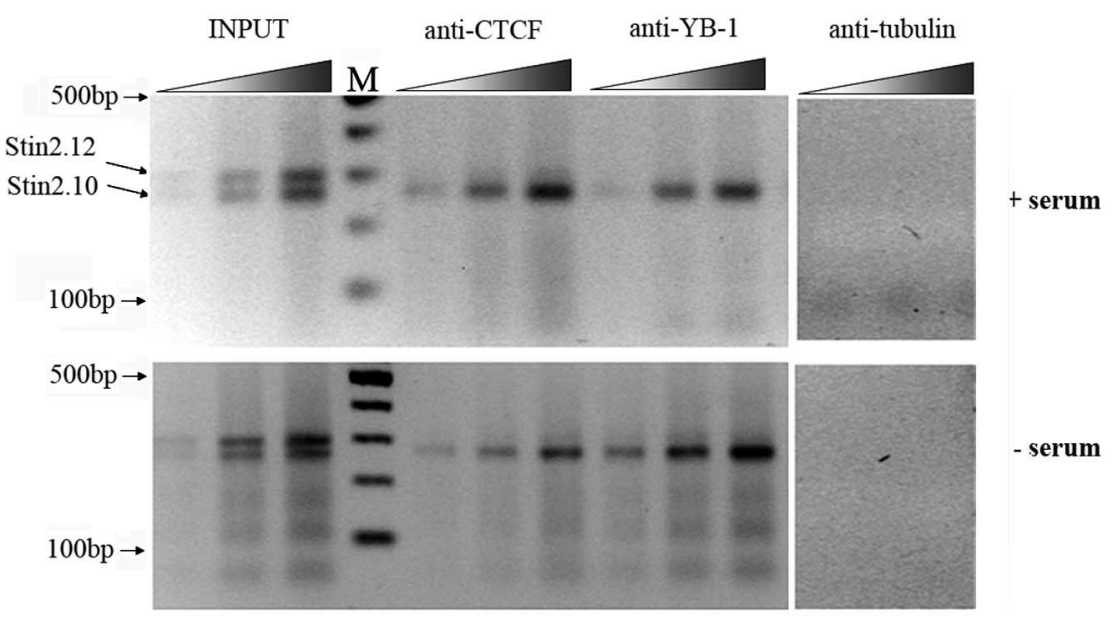

C anti- CTCF anti- YB-1
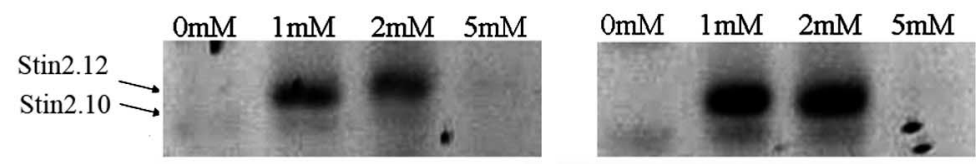

H19
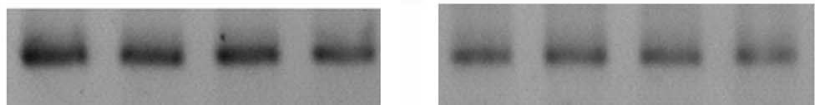

Figure 5. A, CTCF interacts directly with the Stin2 VNTR. EMSA analysis was performed as described in Materials and Methods with Stin2.9 (i), Stin2.10 (ii), and Stin2.12 (iii). Lanes: F, Free probes; 1, YB-1 glutathione S-transferase (GST); 2, YB-1 GST plus cold probe (competitor); 3 , bvCTCF $(0.5 \mu \mathrm{g}) ; 4$, bvCTCF $(1 \mu \mathrm{g}) ; 5$, bvCTCF $(2 \mu \mathrm{g}) ; 6$, bvCTCF $(1 \mu \mathrm{g})$ plus $1 \times$ competitor (H19 ICR); 7 , bvCTCF $(1 \mu \mathrm{g})$ plus $10 \times$ competitor (H19 ICR); 8 , bvCTCF $(1 \mu \mathrm{g})$ plus $100 \times$ competitor (H19ICR). The small dark bands indicated by asterisks are most likely primer dimers; the complex indicated by an open triangle possibly represents a nonspecific DNAprotein complex, because it did not compete with the specific competitor. B, ChIP analysis of the interactions of CTCF and YB-1 with the Stin2 VNTR in JAr cells. Antibodies were used in increasing concentration $(2,4$, and $8 \mu \mathrm{g})$ based on titration of antibody, which was determined as in Materials and Methods. Both CTCF and YB-1 interact with only the Stin2.10 allele in vivo in cells grown in the presence of serum (top) or absence of serum (bottom). C, CTCF and YB-1 bind to the Stin2 VNTR after treatment with LiCl. JAr cells were treated with LiCl, as described in Materials and Methods, and were then used for ChIP assays. LiCl modulated a "switch" of binding between the two alleles, as shown by the appearance of the Stin2.12 band with both anti-CTCF and YB- 1 antibodies used at 2, 4, and $8 \mu \mathrm{g}$. As a control, the characterized CTCF binding domain H19 was also analyzed, and no change was observed in binding in response to LiCl. 


\section{A. Potential CTCF binding sites within the Stin2.12 VNTR}

Sequence
1

B. CTCF "consensus":

\section{CCGCNNGGNGGCAG}

C. Comparison of CTCF sites in Stin 2.12 with the "consensus"

$\begin{aligned} \begin{array}{r}\text { Element } \\ \text { identity }\end{array} & \text { CTCF site } \\ \text { a } & \\ \text { b } & \\ \text { c } & \\ d & \text { site 1 } \\ \text { e } & \\ \text { f } & \text { Site 2 } \\ \text { d } & \text { Site } 3 \\ \text { d } & \text { site } 4 \\ \text { g } & \\ d & \end{aligned}$

RP 12 able that direct binding of CTCF to the SLC6A4 VNTR could also be important for regulation of SLC6A4 function.

Exogenous expression of CTCF in JAr cells increased SLC6A4 mRNA (Fig. 4A). Consistent with this, overexpression of CTCF increased SLC6A4 protein concentration (Fig. $4 B$ ). It is likely that CTCF acts at least in part via the intron 2 VNTR, because all three VNTRs respond to CTCF in a reporter assay (Fig. $3 B$ ). Interestingly, much higher levels of induction can be achieved from the Stin2.12 variant. Exogenous YB-1 did not lead to activation of endogenous SLC6A4 (data not shown), although it could still activate all three VNTRs in a reporter assay (Fig. 3B). Similarly to CTCF, YB-1 had stronger effects on the Stin 2.12 variant. This discrepancy may be explained by a more complex regulation of the endogenous gene, containing various regulatory elements within the same gene. In agreement with our previous report (Lovejoy et al., 2003; Klenova et al., 2004), coexpression of CTCF and YB-1 in JAr cells resulted in abrogation of the effects of YB-1 and CTCF in a reporter gene assay with all three VNTR variants. It is possible that mechanisms involving both interaction between CTCF and YB-1 and direct competition for the VNTR occur, leading to the inhibition of the ex-

vide a direct link between drug action and a predisposing genetic polymorphic domain in the same clinical disorder.

We demonstrate that variation in SLC6A4 expression in response to $\mathrm{LiCl}$ was correlated with differential YB- 1 and CTCF expression. Our hypothesis was that CTCF and YB- 1 control the transcriptional properties of the intron 2 VNTR, which can be modulated by LiCl. This hypothesis was substantiated by the demonstration that, in a stably transfected JAr cell line model, a reporter gene supported by the VNTRs was a target for LiCl modulation (Fig. $2 \mathrm{~B}$ ). The intron $2 \mathrm{VNTR}$ is one of many potential $\mathrm{LiCl}$ regulatory targets in the SLC6A4 locus; however, the interesting feature of this domain is the clinical correlation with affective disorders. The variation in mRNA expression is likely to be reflected in protein concentration and effect behavioral changes in a similar way to an SSRI (serotonin specific reuptake inhibitor) modulating the effective functional concentration of the transporter.

The transcription factor YB-1, but not CTCF, was previously shown to interact with the SLC6A4 intron 2 VNTR and activate the VNTR in a reporter assay in COS7 and 293T cells, although these do not express an endogenous SLC6A4 gene (Lovejoy et al., 2003; Klenova et al., 2004). In this report, we provide evidence that, in a SLC6A4 positive cell line, JAr, CTCF binds the SLC6A4 VNTR and activates this domain. Furthermore, $\mathrm{LiCl}$ modulates binding of both CTCF and YB-1 to the endogenous intron 2 VNTR in JAr cells. Indeed, inspection of the SLC6A4 VNTR region reveals potential binding sites for CTCF (Fig. 6). Therefore, regulation of the SLC6A4 VNTR may depend on a particular cellular context and involve different mechanisms; one of them, blocking of YB-1 binding to the VNTR, has been described previously (Lovejoy et al., 2003; Klenova et al., 2004). It is conceiv- pression from the reporter gene constructs by YB-1. From these experiments we conclude that (1) CTCF plays an important role in the regulation of SLC6A4 in JAr cells, (2) the effects of CTCF and YB-1 are likely to be relayed in part through the intron 2 VNTR domain, and (3) distinct VNTR elements are differentially regulated by CTCF and YB-1.

Regulation modulated by CTCF and YB-1 may be different on the 12 copy VNTR, suggesting a mechanism by which these transcription factors distinguish the function of these domains. Specifically, (1) the 12 copy VNTR supported lower basal expression in reporter gene assays in the two cell lines tested (Fig. 3A); (2) in vitro CTCF bound with lower affinity to the 12 copy VNTR than to the 9 and 10 copy (Fig. 5A); (3) perhaps most importantly, in the context of SLC6A4 expression in JAr cells, CTCF and YB- 1 are both predominantly bound to the 10 copy allele, which dramatically switched to the 12 copy allele in the presence of $\mathrm{LiCl}$. Because this domain is a transcriptional regulator, it may be one of several cis-acting domains contributing to the differential gene response to stress. There are likely to be multiple regulatory domains in the SLC6A4 gene, which synergize to give tissue-specific and stimulus-inducible gene expression; some of these may also be polymorphic [i.e., the $5^{\prime}$ promoter domain, termed long or short (Heils et al., 1996, 1998)]. Thus, when transcription factors bind to specific alleles in response to a drug or stress, then the correlation must account for polymorphic regulatory domains acting in cis- on the same allele. This may explain in part the conflicting data on the statistical significance of the SLC6A4 intron 2 VNTR with affective disorders.

The location of the VNTR within the SLC6A4 gene strongly suggests that this is the gene whose expression is regulated by this domain. This is consistent with our previous studies, in particular 
differential gene expression supported by the intron 2 VNTR in the CNS in the region that exhibited the initial serotoninergic lineage (MacKenzie and Quinn, 1999). Delineation of the mechanism(s) regulating Stin2 VNTR function and endogenous SLC6A4 expression could be complex. CTCF is involved in the enhancer-blocking function of vertebrate insulators (Bell et al., 1999), has both transcriptional and epigenetic functions in the control of imprinting, and is associated with diseases ranging from Alzheimer's to cancer (Vostrov and Quitschke, 1997; Klenova et al., 2002). YB-1 has been implicated as a regulator of multiple processes such as development, multidrug resistance, oncogenesis, RNA splicing, DNA repair, and immune responses (Gaudreault et al., 2004; Gimenez-Bonafe et al., 2004; Ohba et al., 2004; Tsujimura et al., 2004; Bader and Vogt, 2005; En-Nia et al., 2005; Huang et al., 2005; Matsumoto et al., 2005). The cointeraction of these factors by direct interaction to regulate DNA targets has been observed for other genes (Chernukhin et al., 2000). Differential binding of these factors to the SLC6A4 intron 2 VNTR may predispose individuals to affective disorders by altering the level of SLC6A4 transcription in specific tissues. It is possible that this change may be attributable to posttranslational modifications in CTCF and/or YB-1, which are influenced by $\mathrm{LiCl}$. Alternatively, administration of $\mathrm{LiCl}$ may cause epigenetic changes in the DNA and/or chromatin structure mediated by lithium-sensitive enzymes modifying DNA and chromatin, which allows for changes in the binding properties of CTCF and/or YB-1, or changes in the composition of a complex binding to the SLC6A4 intron 2 VNTR.

The complex nature of the SLC6A4 VNTR is further illustrated because, although SLC6A4 expression was induced by LiCl (Fig. 1), the VNTRs were shown to be repressor elements in a reporter gene assay in a stable cell line model that, on exposure to $\mathrm{LiCl}$, further inhibited their activity (Fig. 2B). In this context, isolation of these elements from their natural gene environment might alter VNTR properties. It will be important to address how the VNTR functions in the context of a promoter fragment encompassing the $5^{\prime}$ promoter and the intronic domain that is analyzed in our current study. Furthermore, there is a $5^{\prime}$ promoter variant, termed the 5HTTLPR, also correlated with genetic predisposition to similar neurological conditions as the intron 2 VNTR (Heils et al., 1996, 1998). The 5HTTLPR has been associated with lithium response (Serretti et al., 2004; Rybakowski et al., 2005), although as yet the intron 2 VNTR has not been examined for lithium response. The 5HTTLPR contains DNA motifs consistent with its binding to CTCF among other transcription factors. Initial data from our group indicate that CTCF will regulate that $5^{\prime}$ domain (J.P.Quinn, personal observations). Therefore, both domains should be considered in clinical correlations for a predisposition to a disorder. These issues will be fully addressed in our future experiments.

We hypothesize the therapeutic action of lithium in affective disorder treatment is mediated in part by modulation of a signal transduction pathway that regulates SLC6A4 expression through interactions of transcription factors with the Stin2 VNTR. Because this is a signal transduction pathway, both genetic and environmental interactions should be factored into future clinical correlation of the SLC6A4 intron 2 VNTR with disorders. Such studies are now gaining prominence in contemporary psychiatric genetics (Eley et al., 2004; McGuffin, 2004).

\section{References}

Agam G, Shaltiel G (2003) Possible role of $3^{\prime}\left(2^{\prime}\right)$-phosphoadenosine-5' phosphate phosphatase in the etiology and therapy of bipolar disorder. Prog Neuropsychopharmacol Biol Psychiatry 27:723-727.
Baastrup PC, Poulsen JC, Schou M, Thomsen K, Amdisen A (1970) Prophylactic lithium: double blind discontinuation in manic-depressive and recurrent-depressive disorders. Lancet 2:326-330.

Bader AG, Vogt PK (2005) Inhibition of protein synthesis by Y box-binding protein 1 blocks oncogenic cell transformation. Mol Cell Biol 25:20952106.

Bradley CC, Blakely RD (1997) Alternative splicing of the human serotonin transporter gene. J Neurochem 69:1356-1367.

Bell AC, West AG, Felsenfeld G (1999) The protein CTCF is required for the enhancer blocking activity of vertebrate insulators. Cell 98:387-396.

Caspi A, Sugden K, Moffitt TE, Taylor A, Craig IW, Harrington H, McClay J, Mill J, Martin J, Braithwaite A, Poulton R (2003) Influence of life stress on depression: moderation by a polymorphism in the 5-HTT gene. Science 301:386-389.

Chao W, Huynh KD, Spencer RJ, Davidow LS, Lee JT (2002) CTCF, a candidate trans-acting factor for X-inactivation choice. Science 295:345-347.

Chen G, Masana MI, Manji HK (2000) Lithium regulates PKC-mediated intracellular cross-talk and gene expression in the CNS in vivo. Bipolar Disord 2:217-236.

Chernukhin IV, Shamsuddin S, Robinson AF, Carne AF, Paul A, El-Kady AI, Lobanenkov VV, Klenova EM (2000) Physical and functional interaction between two pluripotent proteins, the Y-box DNA/RNA-binding factor, YB-1, and the multivalent Zinc-finger factor, CTCF. J Biol Chem 275:29915-29921.

Cho HJ, Meira-Lima I, Cordeiro Q, Michelon L, Sham P, Vallada H, Collier DA (2005) Population-based and family-based studies on the serotonin transporter gene polymorphisms and bipolar disorder: a systematic review and meta-analysis. Mol Psychiatry 10:771-781.

Collier DA, Arranz MJ, Sham P, Battersby S, Vallada H, Gill AK, Sodhi M, Li T, Roberts GW, Smith B, Morton RM, Smith D, Kirov G (1996) The serotonin transporter is a potential susceptibility factor bipolar affectivedisorder. NeuroReport 7:1675-1679.

Eley TC, Sugden K, Corsico A, Gregory AM, Sham P, McGuffin P, Plomin R, Craig IW (2004) Gene-environment interaction analysis of serotonin system markers with adolescent depression. Mol Psychiatry 9:908-915.

En-Nia A, Yilmaz E, Klinge U, Lovett DH, Stefanidis I, Mertens PR (2005) Transcription factor YB-1 mediates DNA polymerase alpha gene expression. J Biol Chem 280:7702-7711.

Filippova GN, Fagerlie S, Klenova EM, Myers C, Dehner Y, Goodwin G, Neiman PE, Collins SJ, Lobanenkov VV (1996) An exceptionally conserved transcriptional repressor, CTCF, employs different combinations of zinc fingers to bind diverged promoter sequences of avian and mammalian c-myc oncogenes. Mol Cell Biol 16:2802-2813.

Fiskerstrand CE, Lovejoy EA, Quinn JP (1999) An intronic polymorphic domain often associated with susceptibility to affective disorders has allele dependent differential enhancer activity in embryonic stem cells. FEBS Lett 458:171-174.

Gaudreault I, Guay D, Lebel M (2004) YB-1 promotes strand separation in vitro of duplex DNA containing either mispaired bases or cisplatin modifications, exhibits endonucleolytic activities and binds several DNA repair proteins. Nucleic Acids Res 32:316-327.

Gimenez-Bonafe P, Fedoruk MN, Whitmore TG, Akbari M, Ralph JL, Ettinger S, Gleave ME, Nelson CC (2004) YB-1 is upregulated during prostate cancer tumor progression and increases P-glycoprotein activity. Prostate 59:337-349.

Heils A, Teufel A, Petri S, Seemann M, Bengel D, Balling U, Riederer P, Lesch KP (1995) Functional promoter and polyadenylation site mapping of the human serotonin (5-HT) transporter gene. J Neural Transm Gen Sect 102:247-254.

Heils A, Teufel A, Petri S, Stober G, Riederer P, Bengel D, Lesch KP (1996) Allelic variation of human serotonin transporter gene expression. J Neurochem 66:2621-2624.

Heils A, Wichems C, Mossner R, Petri S, Glatz K, Bengel D, Murphy DL, Lesch KP (1998) Functional characterization of the murine serotonin transporter gene promoter in serotonergic raphe neurons. J Neurochem 70:932-939.

Huang J, Tan PH, Li KB, Matsumoto K, Tsujimoto M, Bay BH (2005) Y-box binding protein, $\mathrm{YB}-1$, as a marker of tumor aggressiveness and response to adjuvant chemotherapy in breast cancer. Int J Oncol 26:607-613.

Ikonomov OC, Manji HK (1999) Molecular mechanisms underlying mood stabilization in manic-depressive illness: the phenotype challenge. Am J Psychiatry 156:1506-1514. 
Kanduri M, Kanduri C, Mariano P, Vostrov AA, Quitschke W, Lobanenkov $\mathrm{V}$, Ohlsson R (2002) Multiple nucleosome positioning sites regulate the CTCF-mediated insulator function of the H19 imprinting control region. Mol Cell Biol 22:3339-3344.

Klenova E, Scott AC, Roberts J, Shamsuddin S, Lovejoy EA, Bergmann S, Bubb VJ, Royer HD, Quinn JP (2004) YB-1 and CTCF differentially regulate the 5-HTT polymorphic intron 2 enhancer which predisposes to a variety of neurological disorders. J Neurosci 24:5966-5973.

Klenova EM, Nicolas RH, Paterson HF, Carne AF, Heath CM, Goodwin GH, Neiman PE, Lobanenkov VV (1993) CTCF, a conserved nuclear factor required for optimal transcriptional activity of the chicken c-myc gene, is an 11-Zn-finger protein differentially expressed in multiple forms. Mol Cell Biol 13:7612-7624.

Klenova EM, Morse III HC, Ohlsson R, Lobanenkov VV (2002) The novel BORIS + CTCF gene family is uniquely involved in the epigenetics of normal biology and cancer. Semin Cancer Biol 12:399-414.

Kohno K, Izumi H, Uchiumi T, Ashizuka M, Kuwano M (2003) The pleiotropic functions of the Y-box-binding protein, YB-1. BioEssays 25:691698.

Kuo MH, Allis CD (1999) In vivo cross-linking and immunoprecipitation for studying dynamic protein:DNA associations in a chromatin environment. Methods 19:425-433.

Lasky-Su JA, Faraone SV, Glatt SJ, Tsuang MT (2005) Meta-analysis of the association between two polymorphisms in the serotonin transporter gene and affective disorders. Am J Med Genet B Neuropsychiatr Genet 133:110-115.

Lerer B, Macciardi F, Segman RH, Adolfsson R, Blackwood D, Blairy S, Del Favero J, Dikeos DG, Kaneva R, Lilli R, Massat I, Milanova V, Muir W, Noethen M, Oruc L, Petrova T, Papadimitriou GN, Rietschel M, Serretti A, Souery D, et al. (2001) Variability of 5-HT2C receptor cys 23 ser polymorphism among European populations and vulnerability to affective disorder. Mol Psychiatry 6:579-585.

Lovejoy EA, Scott AC, Fiskerstrand CE, Bubb VJ, Quinn JP (2003) The serotonin transporter intronic VNTR enhancer correlated with a predisposition to affective disorders has distinct regulatory elements within the domain based on the primary DNA sequence of the repeat unit. Eur J Neurosci 17:417-420.

MacKenzie A, Quinn J (1999) A serotonin transporter gene intron 2 polymorphic region, correlated with affective disorders, has allele-dependent differential enhancer-like properties in the mouse embryo. Proc Natl Acad Sci USA 96:15251-15255.

Matsumoto K, Abiko S, Ariga H (2005) Transcription regulatory complex including YB-1 controls expression of mouse matrix metalloproteinase-2 gene in NIH3T3 cells. Biol Pharm Bull 28:1500-1504.

McGuffin P (2004) Nature and nurture interplay: schizophrenia. Psychiatr Prax 31 [Suppl 2]:S189-S193.

Ohba H, Chiyoda T, Endo E, Yano M, Hayakawa Y, Sakaguchi M, Darnell RB,
Okano HJ, Okano H (2004) Sox21 is a repressor of neuronal differentiation and is antagonized by YB-1. Neurosci Lett 358:157-160.

Ohlsson R, Renkawitz R, Lobanenkov V (2001) CTCF is a uniquely versatile transcription regulator linked to epigenetics and disease. Trends Genet $17: 520-527$.

Rybakowski JK, Suwalska A, Czerski PM, Dmitrzak-Weglarz M, LeszczynskaRodziewicz A, Hauser J (2005) Prophylactic effect of lithium in bipolar affective illness may be related to serotonin transporter genotype. Pharmacol Rep 57:124-127.

Sambrook S, Russell DW (2001) Molecular cloning: a laboratory manual, Ed 3. Cold Spring Harbor, NY: Cold Spring Harbor Laboratory Press.

Serretti A, Malitas PN, Mandelli L, Lorenzi C, Ploia C, Alevizos B, Nikolaou C, Boufidou F, Christodoulou GN, Smeraldi E (2004) Further evidence for a possible association between serotonin transporter gene and lithium prophylaxis in mood disorders. Pharmacogenomics J 4:267-273.

Shaldubina A, Agam G, Belmaker RH (2001) The mechanism of lithium action: state of the art, ten years later. Prog Neuropsychopharmacol Biol Psychiatry 25:855-866.

Shamir A, Shaltiel G, Greenberg ML, Belmaker RH, Agam G (2003) The effect of lithium on expression of genes for inositol biosynthetic enzymes in mouse hippocampus; a comparison with the yeast model. Brain Res Mol Brain Res 115:104-110.

Swamynathan SK, Varma BR, Weber KT, Guntaka RV (2002) Targeted disruption of one allele of the Y-box protein gene, Chk-YB-1b, in DT40 cells results in major defects in cell cycle. Biochem Biophys Res Commun 296:451-457.

Tamura T, Morinobu S, Okamoto Y, Kagaya A, Yamawaki S (2002) The effects of antidepressant drug treatments on activator protein-1 binding activity in the rat brain. Prog Neuropsychopharmacol Biol Psychiatry 26:375-381.

Tsuji S, Morinobu S, Tanaka K, Kawano K, Yamawaki S (2003) Lithium, but not valproate, induces the serine/threonine phosphatase activity of protein phosphatase $2 \mathrm{~A}$ in the rat brain, without affecting its expression. J Neural Transm 110:413-425.

Tsujimura S, Saito K, Nakayamada S, Nakano K, Tsukada J, Kohno K, Tanaka Y (2004) Transcriptional regulation of multidrug resistance-1 gene by interleukin-2 in lymphocytes. Genes Cells 9:1265-1273.

Vostrov AA, Quitschke WW (1997) The zinc finger protein CTCF binds to the APBbeta domain of the amyloid beta-protein precursor promoter. Evidence for a role in transcriptional activation. J Biol Chem 272:3335333359.

Wolffe AP (1994) Structural and functional properties of the evolutionarily ancient Y-box family of nucleic acid binding proteins. BioEssays 16:245251.

Wolffe AP, Tafuri S, Ranjan M, Familari M (1992) The Y-box factors: a family of nucleic acid binding proteins conserved from Escherichia coli to man. New Biol 4:290-298. 